\title{
IeDER
}

Tracing people living with HIV who are lost to follow-up at ART programs in Southern Africa: Study protocol

\begin{tabular}{|c|c|}
\hline Authors & 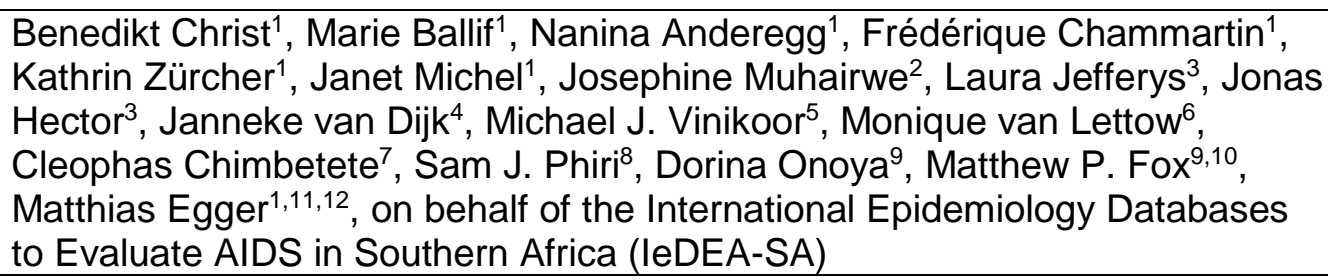 \\
\hline Affiliations & $\begin{array}{l}1 \text { Institute of Social and Preventive Medicine, University of Bern, Bern, } \\
\text { Switzerland } \\
2 \text { SolidarMed, Maseru, Lesotho } \\
3 \text { SolidarMed, Pemba, Mozambique } \\
4 \text { SolidarMed, Masvingo, Zimbabwe } \\
5 \text { Centre for Infectious Diseases Research in Zambia, Lusaka, Zambia } \\
6 \text { Dignitas International, Zomba, Malawi } \\
7 \text { Newlands Clinic, Harare, Zimbabwe } \\
8 \text { Lighthouse Trust Clinic, Lilongwe, Malawi } \\
9 \text { Health Economics and Epidemiology Research Office, Department of } \\
\text { Internal Medicine, School of Clinical Medicine, Faculty of Health Sciences, } \\
\text { University of the Witwatersrand } \\
10 \text { Departments of Epidemiology and Global Health, Boston University } \\
\text { School of Public Health, Boston, MA, USA } \\
11 \text { Centre for Infectious Disease Research and Epidemiology, University of } \\
\text { Cape Town, Cape Town, South Africa } \\
12 \text { Population Health Sciences, Bristol Medical School, University of Bristol, } \\
\text { Bristol, United Kingdom }\end{array}$ \\
\hline $\begin{array}{l}\text { Corresponding } \\
\text { authors }\end{array}$ & $\begin{array}{l}\text { Matthias Egger: matthias.egger@ispm.unibe.ch } \\
\text { Marie Ballif: marie.ballif@ispm.unibe.ch }\end{array}$ \\
\hline Background & $\begin{array}{l}\text { The successful treatment of people living with HIV (PLHIV) and the } \\
\text { monitoring and evaluation of antiretroviral therapy (ART) programs both } \\
\text { depend on regular and complete patient follow-up }(1,2) \text {. Indeed, retention in } \\
\text { care is an important component in the HIV prevention, treatment and care } \\
\text { cascade and one of the key indicators used for the monitoring of ART } \\
\text { programs. ART programs with high rates of loss to follow-up and poor } \\
\text { ascertainment of deaths in PLHIV who are lost will underestimate mortality of } \\
\text { all patients starting ART. Naïve survival analyses censoring patients lost to } \\
\text { follow-up will be biased because mortality is assumed to be identical than } \\
\text { among patients remaining in care (3). Analyses restricted to patients } \\
\text { remaining in care will underestimate mortality among all patients who started } \\
\text { ART. }\end{array}$ \\
\hline
\end{tabular}




\begin{tabular}{|c|c|}
\hline & $\begin{array}{l}\text { Biased estimates of program-level mortality hamper the evaluation of single } \\
\text { programs and the comparison between programs, settings and countries } \\
(4,5) \text {. Different methods are available to correct estimates of program-level } \\
\text { mortality for loss to follow-up, including linkages of patients who are lost to } \\
\text { ART programs to death registries, or, in the absence of such registries, } \\
\text { tracing of patients lost to follow-up to ascertain their vital status }(3,6-8) \text {. Such } \\
\text { studies will be important in countries with limited, decentralized, or poorly } \\
\text { functioning death registries. }\end{array}$ \\
\hline Aims & $\begin{array}{l}\text { To determine through tracing the status of PLHIV classified as lost to follow- } \\
\text { up at ART programs that are part of the International epidemiology } \\
\text { Databases to Evaluate AIDS in Southern Africa (IeDEA-SA); and thus to } \\
\text { obtain accurate programs' retention in care and mortality estimates. }\end{array}$ \\
\hline Hypothesis & $\begin{array}{l}\text { Silent transfers and mortality are largely underestimated in routinely collected } \\
\text { data from ART programs. The poor ascertainment of deaths, transfers and } \\
\text { disengagement from care among patients lost to follow-up in ART programs } \\
\text { impacts on the accuracy of estimates for retention in care and treatment } \\
\text { outcomes, including mortality. }\end{array}$ \\
\hline Objectives & $\begin{array}{l}\text { 1) To trace PLHIV classified as lost to follow-up in leDEA-SA participating } \\
\text { ART programs in Lesotho, Malawi, Mozambique, Zambia, South Africa, } \\
\text { and Zimbabwe to determine their status (alive or not, on ART or not) } \\
\text { according to a standardized tracing procedure. } \\
\text { 2) To estimate mortality and silent transfers among patients lost to follow-up } \\
\text { by time from starting ART, by CD4 cell count at start of ART, by sex, and } \\
\text { by age. } \\
\text { 3) To estimate program-level mortality taking into account mortality among } \\
\text { patients lost to follow-up, including for patients who stopped ART, } \\
\text { interrupted ART or transferred to another ART program. }\end{array}$ \\
\hline Methods & $\begin{array}{l}\text { Aim } \\
\text { To trace a stratified random sample of approximately } 500 \text { PLHIV who are lost } \\
\text { to follow-up at each participating ART program. } \\
\text { Sampling procedure and eligibility criteria } \\
\text { Prior to sampling, all participating ART programs will provide the leDEA-SA } \\
\text { datacenter at the University of Bern, Switzerland, with a list of all patients } \\
\text { fulfilling the following criteria: } \\
\text { - Patient started ART before 01.01.2014 and was on ART on } \\
\text { 01.01.2014 (i.e. not defined as lost to follow-up on 01.01.2014) } \\
\text { or } \\
\text { Patient started ART between 01.01.2014 and 31.03.2017 (including) } \\
\text { AND } \\
\text { Patient defined as lost to follow-up between 02.01.2014 and } \\
\text { 30.06.2017 (including), meaning that the last time the patient was } \\
\text { seen at the clinic is until } 31.03 .2017 \text { (including). }\end{array}$ \\
\hline
\end{tabular}




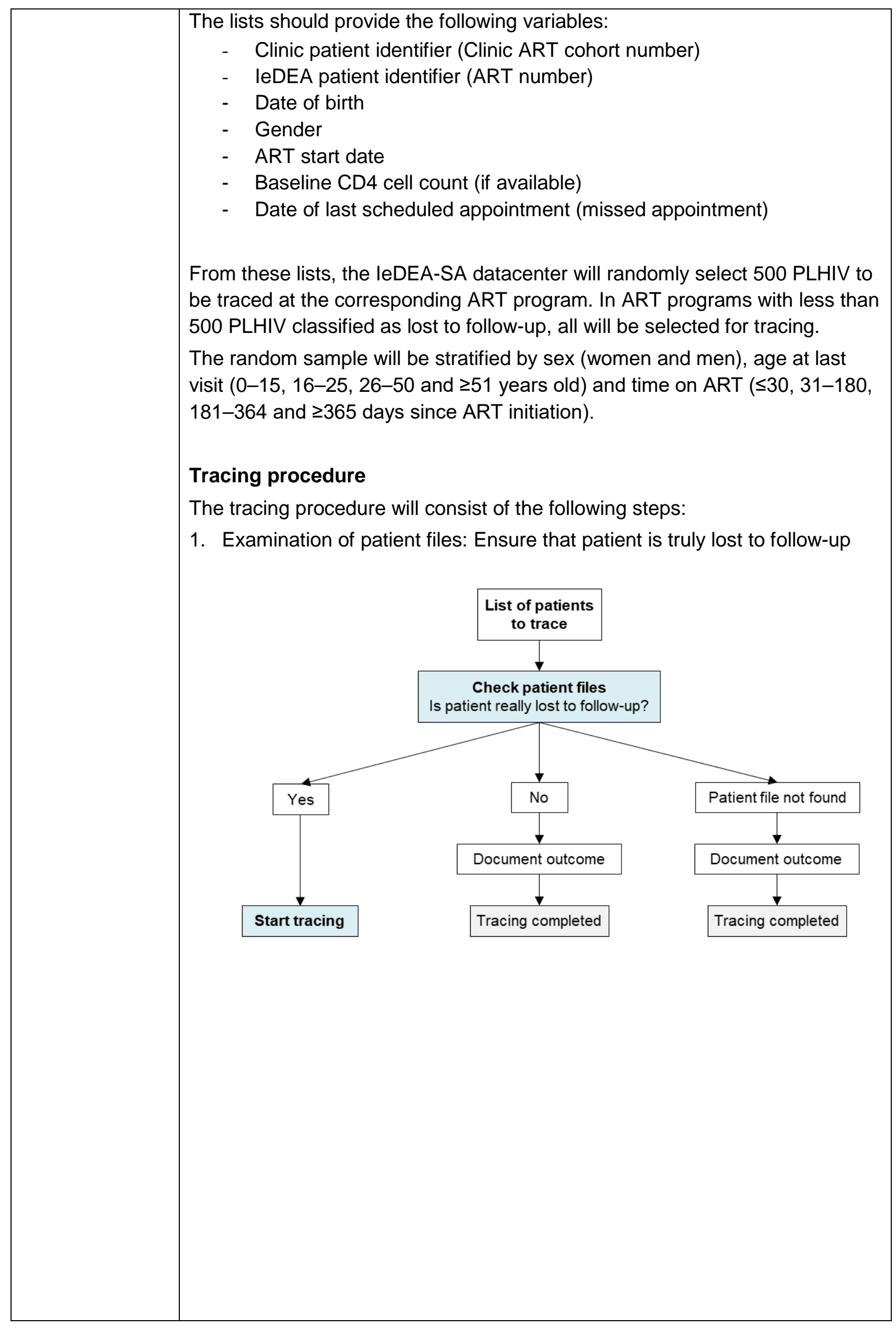


2. Tracing

2.1 Text messages/SMS to arrange phone calls or home visits (if available)

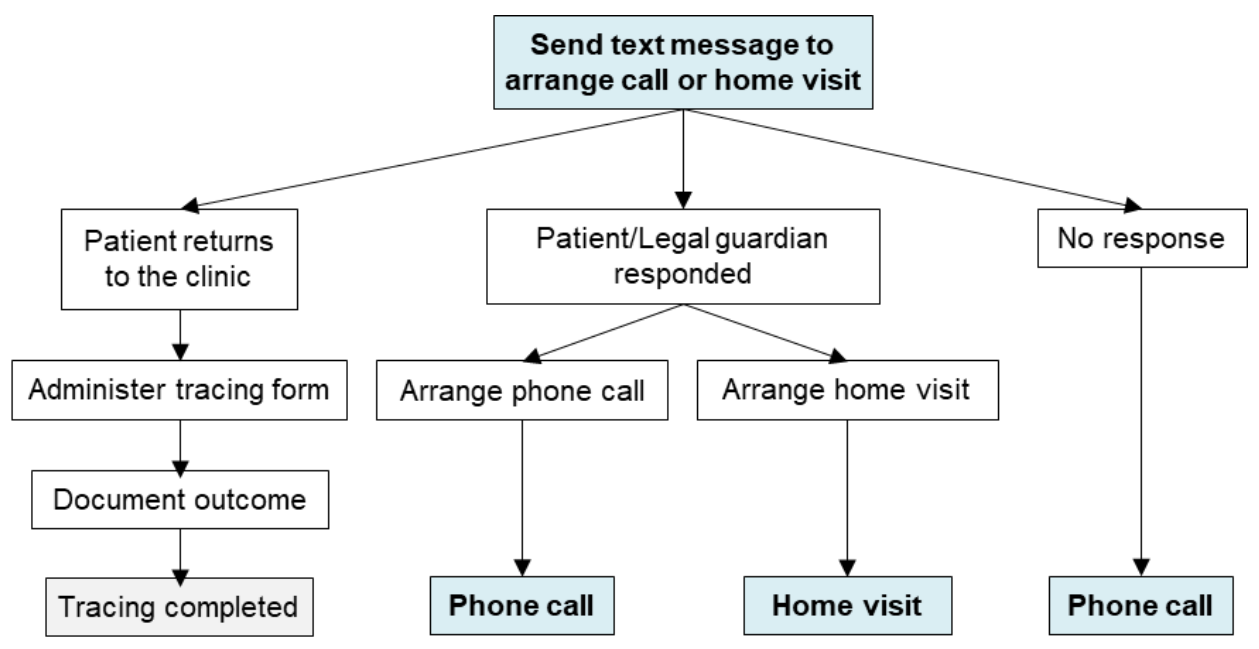

2.2 Phone calls (if available)

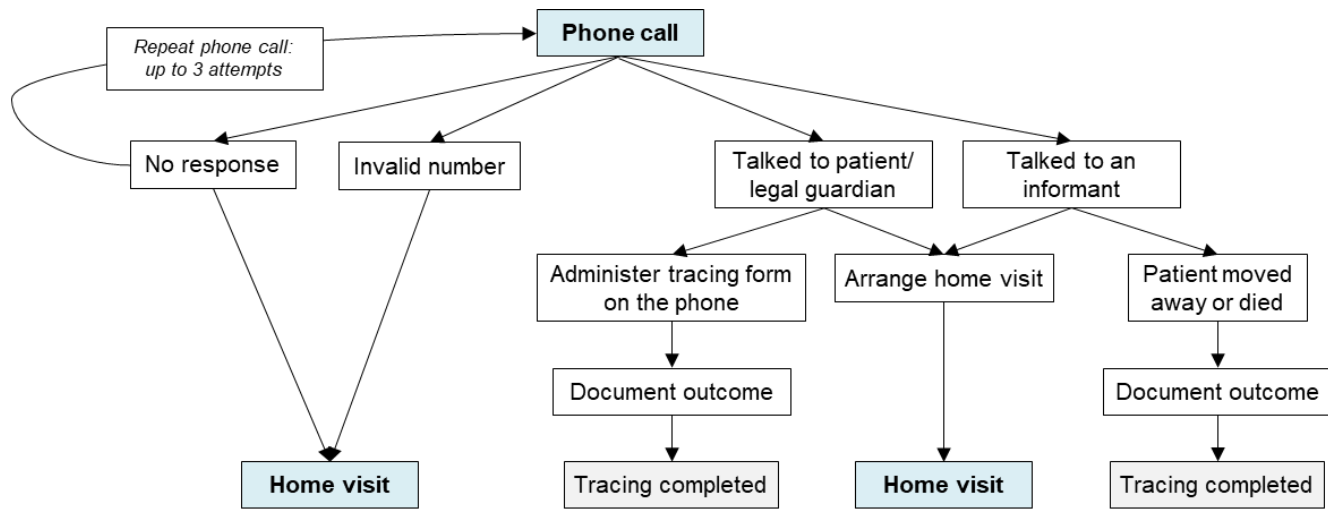

2.3 Home visits (if available)

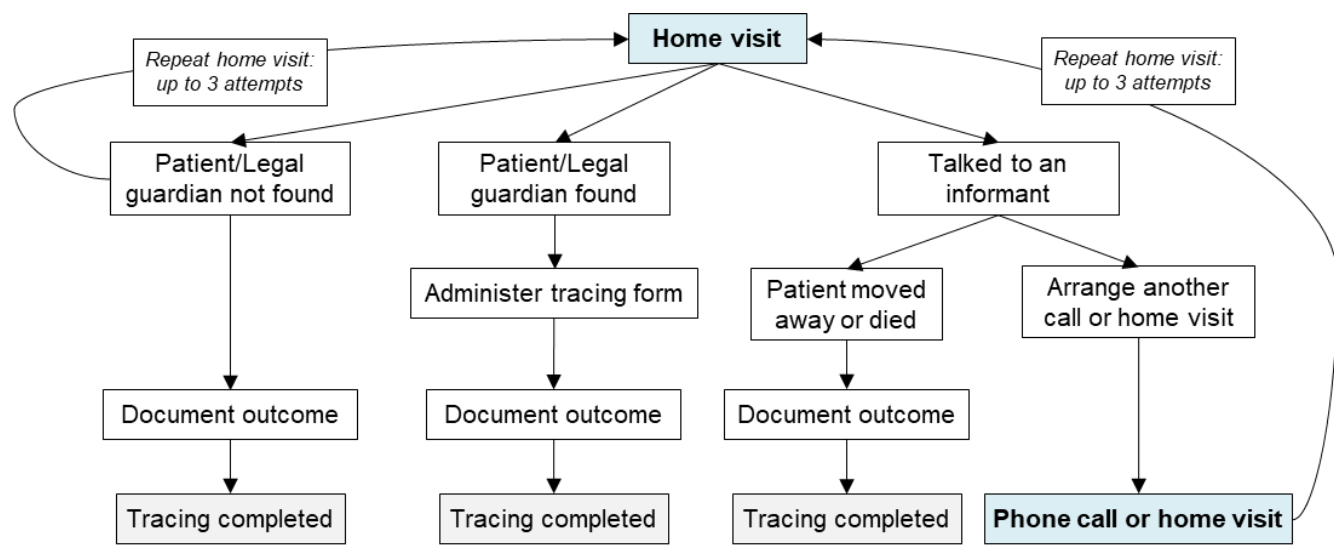

All tracing outcomes will be documented using the tracing form (see Annexe: Tracing Form). 


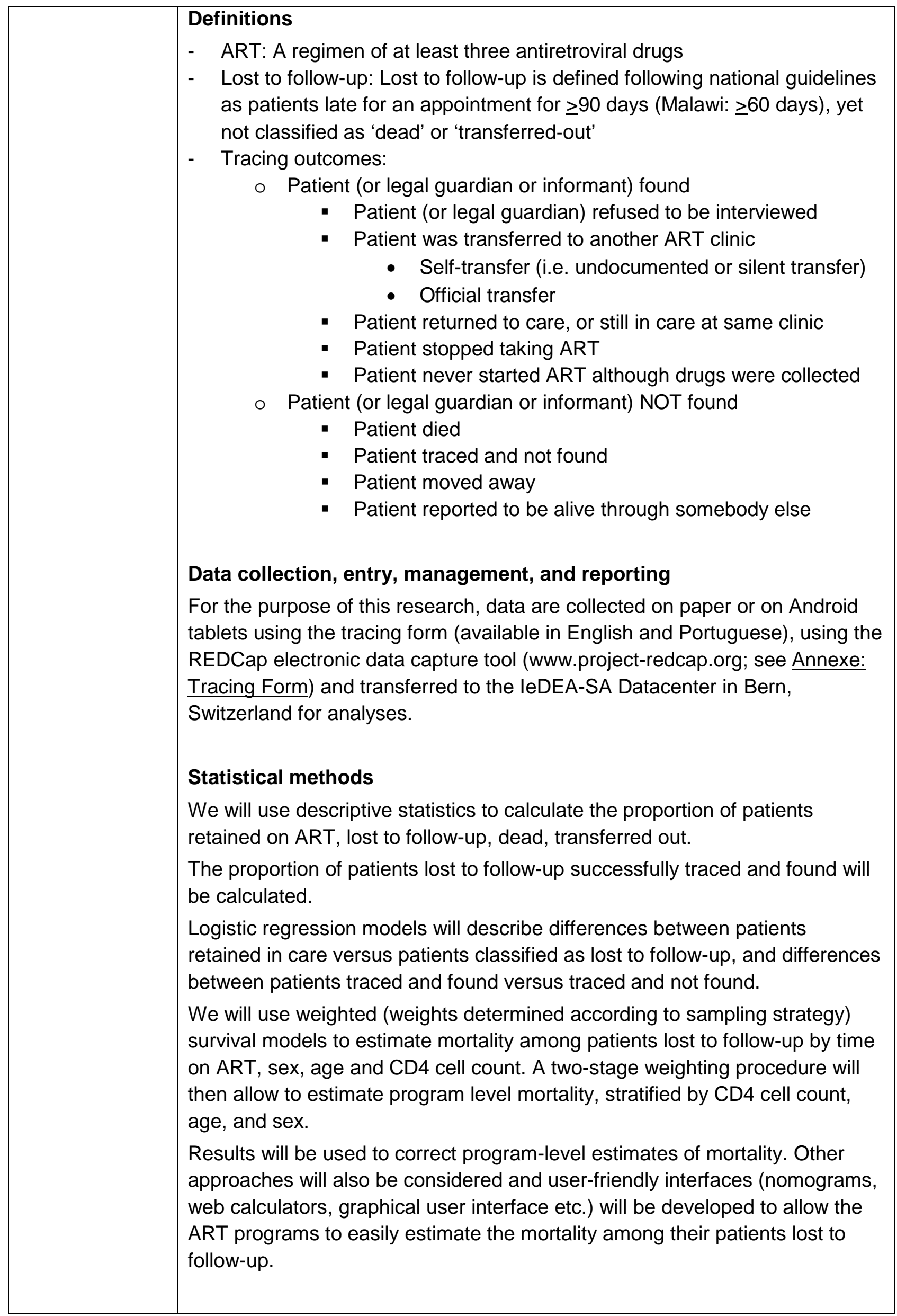




\begin{tabular}{|c|c|}
\hline & $\begin{array}{l}\text { Ethical considerations } \\
\text { This project has been approved by the Kantonale Ethikkommission in Bern } \\
\text { (KEK) as part of leDEA-SA core activities. } \\
\text { Tracing is part of routine care and therefore, all participants (or legal } \\
\text { guardians) consented to be traced if needed upon ART initiation. } \\
\text { The data will be used according to the highest legal and ethical standards } \\
\text { and as such, significant effort will be devoted to ensure compliance with all } \\
\text { national and international regulations and guidelines for human research. } \\
\text { Collaborators accessing the data received mandatory training on Protecting } \\
\text { Human Research Subjects and Information Security Awareness. } \\
\text { All received data will be stored on secure servers at the University of Bern. } \\
\text { Only individuals who work with the data, will have access to the data. The } \\
\text { study dataset is coded and protected prior to transfer to the leDEA-SA } \\
\text { Datacenter in Bern, Switzerland. }\end{array}$ \\
\hline $\begin{array}{l}\text { Ownership of } \\
\text { data }\end{array}$ & $\begin{array}{l}\text { Each ART program retains ownership of their original data throughout their } \\
\text { participation and is able to analyze and submit publications on their own data. } \\
\text { For the purpose of this study, the leDEA-SA Datacenter in Bern, Switzerland } \\
\text { will analyze the collected data and submit publications in collaboration with } \\
\text { the ART programs. }\end{array}$ \\
\hline References & $\begin{array}{l}\text { 1. Geng EH, Odeny TA, Lyamuya R, Nakiwogga-Muwanga A, Diero L, } \\
\text { Bwana M, et al. Retention in Care and Patient-Reported Reasons for } \\
\text { Undocumented Transfer or Stopping Care Among HIV-Infected Patients } \\
\text { on Antiretroviral Therapy in Eastern Africa: Application of a Sampling- } \\
\text { Based Approach. Clin Infect Dis Off Publ Infect Dis Soc Am. 2016 } \\
\text { Apr;62(7):935-44. } \\
\text { 2. Fox MP, Rosen S. Patient retention in antiretroviral therapy programs up } \\
\text { to three years on treatment in sub-Saharan Africa, 2007-2009: systematic } \\
\text { review. Trop Med Int Health TM IH. 2010 Jun;15 Suppl 1(s1):1-15. } \\
\text { 3. Chammartin F, Zürcher K, Keiser O, Weigel R, Chu K, Kiragga AN, et al. } \\
\text { Outcomes of Patients Lost to Follow-up in African Antiretroviral Therapy } \\
\text { Programs: Individual Patient Data Meta-analysis. Clin Infect Dis Off Publ } \\
\text { Infect Dis Soc Am. 2018 Nov;67(11):1643-52. } \\
\text { 4. Egger M, Spycher BD, Sidle J, Weigel R, Geng EH, Fox MP, et al. } \\
\text { Correcting mortality for loss to follow-up: a nomogram applied to } \\
\text { antiretroviral treatment programmes in sub-Saharan Africa. PLoS Med. } \\
\text { 2011/01/27 ed. 2011 Jan;8(1):e1000390. } \\
\text { 5. Anderegg N, Hector J, Jefferys LF, Burgos-Soto J, Hobbins MA, Ehmer J, } \\
\text { et al. Loss to follow-up correction increased mortality estimates in HIV- } \\
\text { positive people on antiretroviral therapy in Mozambique. J Clin Epidemiol. } \\
\text { 2020 Dec 1;128:83-92. } \\
\text { Forster M, Bailey C, Brinkhof MW, Graber C, Boulle A, Spohr M, et al. } \\
\text { Electronic medical record systems, data quality and loss to follow-up: } \\
\text { survey of antiretroviral therapy programmes in resource-limited settings. } \\
\text { Bull World Health Organ. 2009/01/15 ed. 2008 Dec;86(12):939-47. } \\
\text { 7. Etoori D, Wringe A, Kabudula CW, Renju J, Rice B, Gomez-Olive FX, et } \\
\text { al. Misreporting of Patient Outcomes in the South African National HIV }\end{array}$ \\
\hline
\end{tabular}




\begin{tabular}{|l|l|}
\hline & $\begin{array}{l}\text { Treatment Database: Consequences for Programme Planning, } \\
\text { Monitoring, and Evaluation. Front Public Health [Internet]. 2020 Apr;8. } \\
\text { Available from: https://pubmed.ncbi.nlm.nih.gov/32318534/ }\end{array}$ \\
8. $\begin{array}{l}\text { Holmes CB, Sikazwe I, Sikombe K, Eshun-Wilson I, Czaicki N, Beres LK, } \\
\text { et al. Estimated mortality on HIV treatment among active patients and } \\
\text { patients lost to follow-up in 4 provinces of Zambia: Findings from a } \\
\text { multistage sampling-based survey. Rosen S, editor. PLOS Med. } 2018 \\
\text { Jan;15(1):e1002489. }\end{array}$ \\
\hline
\end{tabular}




\section{Tracing Form}

Record ID

\section{IeDEA-SA Site}

leDEA-SA site

$\bigcirc$ Lesotho SMART

Malawi Dignitas

Malawi Lighthouse

Mozambique SMART

South Africa Themba Lethu

South Africa Hlabisa

$\bigcirc$ Zambia CIDRZ

$\bigcirc$ Zimbabwe SMART

$\bigcirc$ Zimbabwe Newlands

\section{Information on tracer}

Tracer identifier

(This code is specific to the tracer. The code should be provided by the site to ensure anonymity. Example: Tracer 1, Tracer 2, etc.)

Tracer background
Nurse
Social worker
$\bigcirc$ Health surveillance assistant
Activist
$\bigcirc$ Field tracer
$\bigcirc$ Expert client
Village health worker
$\bigcirc$ Lay counselor
$\bigcirc$ Other

Specifiy tracer background

\section{Patient data}

Patient identifier at the clinic

leDEA patient identifier

Gender

Male

Female

$\bigcirc$ Unknown

Is the date of birth known?

$\bigcirc$ Yes

No, but age is known in years

$\bigcirc$ No, but age is known in months (for young children)

$\bigcirc$ No, unknown date of birth and unknown age

Date of birth (dd/mm/yyyy)

(If month and day are unknown, record 15 June; if only day is unknown, record 15)

Age in years 
Age in months

Caregiver details provided?

Yes

No

Relationship of caregiver to patient

Village/community where patient lives

District

Province/region

Time needed from patient's home to facility (one way)

Less than 1 hour

$\bigcirc$ Up to half a day

More

Unknown

Name of health care centre, clinic or hospital

attended by patient for HIV care

Date of last visit, when patient was seen at the facility (dd/mm/yyyy)

Date of missed appointment ( $\mathrm{dd} / \mathrm{mm} / \mathrm{yyyy})$

(Record as much of the date as possible; if month and day are unknown, record 15 June; if only day is unknown, record 15)

\section{Tracing log}

Is the patient confirmed lost to follow-up?

Yes

No

Unknown, patient file not found (END)

(Definition lost to follow-up: Patient not seen

for at least 90 days after the last missed

appointment ( 60 days for Malawi Lighthouse and

Dignitas) Definition END: No tracing can be done)

\section{A: Text message (SMS or other instant message) - one attempt only}

Text message used to trace patient:

$\bigcirc$ Yes

No

Date of text message sent ( $\mathrm{dd} / \mathrm{mm} / \mathrm{yyyy})$

Result

(Wait minimum one day, but maximum seven days, for the patient's response)
Phone call arranged by text message
Home visit arranged by text message
No response to text message
$\bigcirc$ Patient spontaneously returned to the facility after having received the text message
$\bigcirc$ Other
(If you tick "Other", continue tracing log and use comment box at the end of the form to specify "Other".)

Date when patient was seen at the facility?

(dd/mm/yyyy) 


\section{B: Phone call - up to three attempts}

Phone calls used to trace patients:

Attempt 1

Date of phone call ( $d d / m m / y y y y)$

Attempt 1

Communicated with

Other: Specify with whom the tracer communicated

Attempt 1

Phone call result

Invalid number: Is there another number available?

Attempt 2

Date of phone call (dd/mm/yyyy)

Attempt 2

Communicated with

Other: Specify with whom the tracer communicated

Attempt 2

Phone call result

Invalid numer: Is there another number available? $\bigcirc$ Yes

No
Patient
$\bigcirc$ Caregiver
Relative
Nobody
Other
Patient/Caregiver accepted to be interviewed on the phone
Patient/Caregiver refused to be interviewed
Home visit arranged
$\bigcirc$ Invalid number
No response, will be called again
$\bigcirc$ Other
(If you tick "Other", continue tracing log and use comment box at the end of the form to specify "Other".)
$\bigcirc$ Yes
No
Patient
Caregiver
Relative
Nobody
Other

Patient/Caregiver accepted to be interviewed on the phone

Patient/Caregiver refused to be interviewed

Home visit arranged

Invalid number

$\bigcirc$ No response, will be called again

Other

(If you tick "Other", continue tracing log and use comment box at the end of the form to specify "Other".)

$\bigcirc$ Yes

No 
Attempt 3

Date of phone call (dd/mm/yyyy)

Attempt 3

Communicated with

Patient

Caregiver

Relative

Nobody

Other

Other: Specify with whom the tracer communicated

Attempt 3

Phone call result

$\bigcirc$ Patient/Caregiver accepted to be interviewed on the phone

Patient/Caregiver refused to be interviewed

Home visit arranged

Invalid number

No response

Other

(If you tick "Other", continue tracing log and use comment box at the end of the form to specify

"Other".)

\section{C: Home visit - up to three attempts}

Home visits used to trace patients:

Yes

No

Attempt 1

Date of home visit ( $d d / m m / y y y y)$

Attempt 1

Communicated with
Patient
Caregiver
Relative
Nobody
Other

Other: Specify with whom the tracer communicated

Attempt 1

Home visit result
Patient/Caregiver accepted to be interviewed
Patient/Caregiver refused to be interviewed
$\bigcirc$ Patient/Caregiver will be called at new number
$\bigcirc$ Patient not localized at the given address or moved
$\bigcirc$ Patient will be visited again
Other
(If you tick "Other", continue tracing log and use comment box at the end of the form to specify "Other".)

Attempt 2

Date of home visit (dd/mm/yyyy)

(Record as much of the date as possible; if month and day are unknown, record 15 June; if only day is unknown record 15)

Attempt 2

Communicated with
Patient
Caregiver
Relative
Nobody
Other

Other: Specify with whom the tracer communicated 
Attempt 2

Home visit result

Attempt 3

Date of home visit (dd/mm/yyyy)

Attempt 3

Communicated with

Other: Specify with whom the tracer communicated

Attempt 3

Home visit result
Patient/Caregiver accepted to be interviewed

$\bigcirc$ Patient/Caregiver refused to be interviewed

$\bigcirc$ Patient/Caregiver will be called at new number

$\bigcirc$ Patient not localized at the given address or moved

Patient will be visited again

Other

(If you tick "Other", continue tracing log and use comment box at the end of the form to specify "Other".)
Patient

Caregiver

Relative

Nobody

Other
Patient/Caregiver accepted to be interviewed

Patient/Caregiver refused to be interviewed

Patient/Caregiver will be called at new number

Patient not localized at the given address or moved

Patient and nobody else found

Other

(If you tick "Other", continue tracing log and use comment box at the end of the form to specify "Other".)

\section{D: Additional attempt (phone call or visit), in addition to the above-listed attempts (for instance, if new contact details were provided by a relative) - one attempt only}

Additional attempt used to trace the patient:

Date of contact (dd/mm/yyyy)

How was the patient traced?

Communicated with

Other: Specify with whom the tracer communicated

Additional attempt result
Yes
No

Phone call

Visit

Patient

Caregiver

Relative

Nobody

Other
Patient/Caregiver accepted to be interviewed

Patient/Caregiver refused to be interviewed

$\bigcirc$ No response (if phone call); Patient/Caregiver not found (if home visit)

$\bigcirc$ Other

(If you tick "Other", continue tracing log and use comment box at the end of the form to specify "Other".) 


\section{Tracing outcome}

Tracing outcome (part 1)

What is the tracing outcome? (this should reflect the current patient state)

Date of death (dd/mm/yyyy)

Tracing outcome (part 2)

Patient in care at another ART program: Patient was transferred by

Patient stopped taking ART: Date when stopped taking ART (dd/mm/yyyy)
Patient known to be alive

Patient known to have died

$\checkmark$ Vital status of patient unknown

(If month and day are unknown, record 15 June; if only day is unknown, record 15)

$\bigcirc$ Patient never missed a visit at the facility

$\bigcirc$ Patient returned to care at the facility

Patient in care at another ART program

Patient stopped taking ART

$\bigcirc$ Patient never started ART

$\bigcirc$ Patient/Caregiver refused to be interviewed

Tracing attempted but patient and nobody else found

Self-transfer or silent transfer

$\bigcirc$ Official transfer

(If month and day are unknown, record 15 June; if only day is unknown, record 15)

\section{Patient's future intentions}

Planning to return to the clinic

Yes

No, patient refuses to return to care

Unknown

Patient refuses to return to care. Reasons (specify):

\section{Patient`s comments}

Patient's comments

\section{Tracer`s comments}

Tracer's comments 